\title{
An Experimental Simulation to Validate FEM to Predict Transverse Young's Modulus of FRP Composites
}

\author{
V. S. Sai, ${ }^{1}$ M. R. S. Satyanarayana, ${ }^{2}$ V. B. K. Murthy, ${ }^{3}$ G. S. Rao, ${ }^{3}$ and A. S. Prasad ${ }^{4}$ \\ ${ }^{1}$ Mechanical Engineering Department, DVR \& Dr. HS MIC College of Technology, Kanchikacherla, India \\ ${ }^{2}$ Mechanical Engineering Department, GITAM University, Visakhapatnam, India \\ ${ }^{3}$ Mechanical Engineering Department, V. R. Siddhartha Engineering College, Vijayawada, India \\ ${ }^{4}$ Mechanical Engineering Department, K L University, Vijayawada, India
}

Correspondence should be addressed to V. B. K. Murthy; vbkmpublications@yahoo.com

Received 29 May 2013; Accepted 23 September 2013

Academic Editor: Steven Suib

Copyright (C) 2013 V. S. Sai et al. This is an open access article distributed under the Creative Commons Attribution License, which permits unrestricted use, distribution, and reproduction in any medium, provided the original work is properly cited.

\begin{abstract}
Finite element method finds application in the analysis of FRP composites due to its versatility in getting the solution for complex cases which are not possible by exact classical analytical approaches. The finite element result is questionable unless it is obtained from converged mesh and properly validated. In the present work specimens are prepared with metallic materials so that the arrangement of fibers is close to hexagonal packing in a matrix as similar arrangement in case of FRP is complex due to the size of fibers. Transverse Young's moduli of these specimens are determined experimentally. Equivalent FE models are designed and corresponding transverse Young's moduli are compared with the experimental results. It is observed that the FE values are in good agreement with the experimental results, thus validating FEM for predicting transverse modulus of FRP composites.
\end{abstract}

\section{Introduction}

Prediction of transverse young's modulus is challenging in micromechanical analysis of fiber reinforced composites. Most of the analytical models suggested fail in micromechanical analysis as they do not consider the status of fiber in matrix as in state. Exact analytical methods are available for square packing of fibers but limited to perfect interface bond and total interface debond cases. This necessitates the application of finite element method. Symmetrical part of one RVE in square or hexagonal array is usually taken as the geometry of the finite element model. Fabrication of a composite specimen exactly to represent square or hexagonal array of unit cells is highly complex due to the size of fibers. Keeping this limitation in view, the authors of the present work have prepared a composite test specimen with two metals. The base material in which holes are drilled acts as matrix, and the second material taken in the form of wires to be inserted into the holes of base material acts as fiber, and the geometrical accuracy thus is ensured with metals. The literature relevant to the scope of present idea is studied and reviewed as follows.
A large number of analytical models with varying degrees of accuracy are available for prediction of mechanical properties of unidirectional composites starting from simple rule of mixtures (ROM) to methods using elastic energy principles. In general they incorporate certain simplifications of the physical state of materials that resulted in theories which do not logically correlate with the experimental data. ROM works perfectly for predicting longitudinal Young's modulus while the inverse rule of mixtures (IROM) fails to give satisfactory results for transverse Young's modulus for all cases. Modified inverse rule of mixtures (MIROM) has taken into account the lateral contraction of matrix material under tension due to Poisson's effect and accommodated it accordingly [1-3]. Jacquet et al. demonstrated that a combination of ROM and IROM can be adapted to suit theoretical modelling of a composite material by considering a combination of rectangular elements of fibres scattered over entire area of RVE in parallel and series orientation and proposed two models [4]. Halpin-Tsai have developed a semiempirical equation to determine the transverse modulus by taking the shape of the fibre cross-section into consideration as reinforcing efficiency 
factor [5]. Neilson modified the Halpin-Tsai equation by introducing a packing factor $\left(\phi_{\max }\right)$ for square, hexagonal, and random fibre packing arrays [6]. Hirsch model is a combination of both ROM and IROM. When the value of $x=$ 0 , the relation reduces to IROM, and when $x=1$, it reduces to ROM [7]. Kalaprasad et al. mentioned Neilson and Hirsch models in their paper and compared the available experimental data with various analytical models for short sisal-LDPE composites [8]. Morais derived a closed form of expression based on simple mechanics of materials analysis of a repeating square cell for predicting transverse modulus [9]. Shan and Chou have used elasticity theory and derived expressions for exact transverse modulus of a square RVE. Also they have extended the theory to find a solution for fibre matrix debond case using elastic contact model [10]. Mistou et al. observed that the ultrasonic method of testing is efficient, accurate, and easy to conduct in comparison with tests on UTM [11]. Stagni derived a formula for evaluating the effective transverse modulus of multilayered hollow fibre composites and observed that under certain conditions, increase in porosity results in increased transverse modulus [12]. Khelifa et al. compared experimental results of longitudinal and transverse moduli with the values from four micromechanical models of a unidirectional FRP composite. However the analytical results neither matched mutually nor with the experimental results [13]. Li and Wisnom reviewed typical finite element formulations and models for unidirectional composite materials and showed that FEA provides more accurate properties for complicated geometries and constituent property variations [14]. Theocaris et al. proposed a simple numerical homogenization method to predict effective transverse elastic modulus of FRP composites. The authors observed that the results of homogenization are close to the results of mesophase concept and have only limited correlation with Hashin-Rosen model [15]. Karadeniz and Kumlutas made a study of effective thermal expansion coefficients of composite materials by micromechanical FE modelling in ANSYS. The results are compared with other analytical and experimental data. [16]. $\mathrm{Pal}$ and Haseebuddin used FEA to study transverse modulus along with other mechanical properties of FRP composites. Their FEA results are not in agreement with Halpin-Tsai's for all volume fractions at $E_{f} / E_{m}$ around 4 [17]. From the review of these studies, it is observed that available analytical models and FEA results are seldom matching in cases of transverse modulus, and validation of FEA results with exact analytical results seems to have been not well attempted. Also, there has not been any rationalization for comparison and validation of these models. The information regarding fibre arrangement in the test specimen as per RVE modelled in FEA seems to have been left altogether.

Prasad et al. studied and established the capability of FEM in predicting the elastic properties of FRP composites with experimental verification where test specimens are specifically designed and fabricated to match the square RVE modelled in FEA [18]. Keeping the complexities involved in handling the fibres of minute diameter to achieve the required geometrical accuracy, metals are chosen as composite constituents. Transverse moduli results from experimental and FEA are compared with each other for mutual validation. The
TABLE 1: Results of longitudinal Young's moduli of constituent materials tested [18].

\begin{tabular}{lcccc}
\hline $\begin{array}{l}\text { Specimen } \\
\text { description }\end{array}$ & $\begin{array}{c}\text { Test } 1 \\
E_{1}(\mathrm{GPa})\end{array}$ & $\begin{array}{c}\text { Test } 2 \\
E_{1}(\mathrm{GPa})\end{array}$ & $\begin{array}{c}\text { Test } 3 \\
E_{1}(\mathrm{GPa})\end{array}$ & $\begin{array}{c}\text { Average value } \\
(\mathrm{GPa})\end{array}$ \\
\hline $\begin{array}{l}\text { Aluminium } \\
\text { blank }\end{array}$ & 67.501 & 65.521 & 66.418 & 66.48 \\
$\begin{array}{l}\text { Copper wire } \\
\begin{array}{l}\text { Mild steel } \\
\text { wire }\end{array}\end{array}$ & 106.379 & 105.199 & 107.624 & 106.40 \\
\hline
\end{tabular}

present work is an extension of [18] for a hexagonal RVE. These give the confidence in usage of FEA for micromechanical analysis of FRP composites. The novelty of this approach is experimental simulation of FRP composites using metals and facilitating perfect validation of FE results.

\section{Experimentation}

2.1. Preparation of Test Specimen. Analytical methods used for determining mechanical properties of composite materials require a reference for their validity and obviously experimental results provide the answer. Test specimens prepared invariably differ from theoretical models in many ways and there is bound to be disagreement between experimental results and analytical outcome. Fabrication of composites with conventional fibers and matrices close to the mathematical model is complex due to minute fibre diameter. Since the purpose is only to validate the methodology, metals are chosen as constituent materials. The isotropic nature of metals and the ease with which a given geometrical accuracy can be achieved on metals are reasons for choosing metals to prepare a metal composite for the present study. The aim is to make a test specimen close to the mathematical model with a purpose to establish a verifiable relation between theory and practice. Aluminium is chosen as matrix; copper and mild steel are chosen as fibres for preparing the test specimens.

Aluminium flats of $175 * 25 * 10 \mathrm{~mm}$ are procured from the market of Hindalco, India make. Copper wire ( $2 \mathrm{~mm}$ dia.) is of electrical grade and mild steel wire ( $2 \mathrm{~mm}$ dia.) is drawn from blanks of Vizag Steel, India. The purity as certified by the suppliers of all these materials is above $97 \%$. However, keeping the necessity of the experiment in view, all materials are tension tested for determining the Young's modulus. The results are compiled in Table 1.

Three categories of composite specimens are prepared, namely, copper-aluminium, mild steel-aluminium, and voids-aluminium (fiber-like voids). While maintaining the length and width of the specimen as per ASTM D3039/ D3039M-08 [18], the thickness of the specimen is taken as per the machining requirements. $2 \mathrm{~mm}$ diameter holes are drilled across $10 \mathrm{~mm}$ thick faces (along $25 \mathrm{~mm}$ width) as shown in Figure 1. Drilling is done on an NC machine taking sufficient care to maintain designed spacing between the holes. Each sample accommodated 25 holes (12 in one row and 13 in the other) and the spacing of holes is according to the machining limitations. The fiber volume fraction achieved by this arrangement would be $10.89 \%$. $25 \mathrm{~mm}$ long pieces are 




FIGURE 1: Specimen with holes drilled across the width.

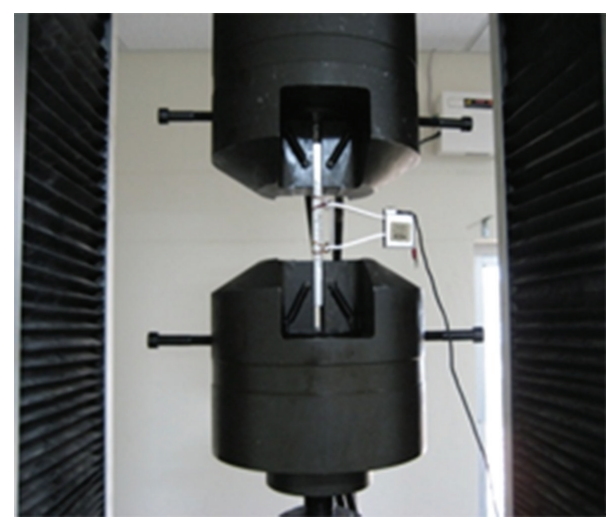

FIGURE 2: Test set-up on UTM.

cut from copper and mild steel wire rolls in sufficient numbers. Wires are driven into the holes by gentle tapping with a nylon mallet. Moderate force is necessitated to drive each fibre piece into the hole which is an indication of generous contact between the interacting surfaces. This also ensured sufficient gripping due to the interference fit of the assembly between fibres and matrix without any mechanical bonding. For each category of the composite, three specimens are prepared bringing the total number of specimens to nine. These specimens are tension tested on a microcomputer controlled electronic UTM of $400 \mathrm{kN}$ capacity as shown in Figure 2 at a crosshead speed of $1 \mathrm{~mm} / \mathrm{min}$. An electronic extensometer of $1 \mu \mathrm{m}$ least count is used to measure the extension and the test data is recorded automatically.

2.2. FE Approach. An RVE in the form of a hexagonal unit cell in cross-section is adapted for analysis and a one-fourth unit cell is modelled by taking the advantage of symmetry. The dimensions of the cell are $250 * 100 * 57.74$ units and fibre radius is 10 . Scaling up of cell size is done for convenience of analysis, without loss of proportionality. The present problem is modelled in ANSYS straight away without resorting to any other programming routines. SOLID 20 NODE 95 Element of ANSYS is used to create FE mesh which is a quadratic brick element that is best suited for curved boundaries. Mesh refinements are made with different element edge lengths and convergence is verified at maximum mismatch conditions. It is observed that at element edge lengths 4 and below the

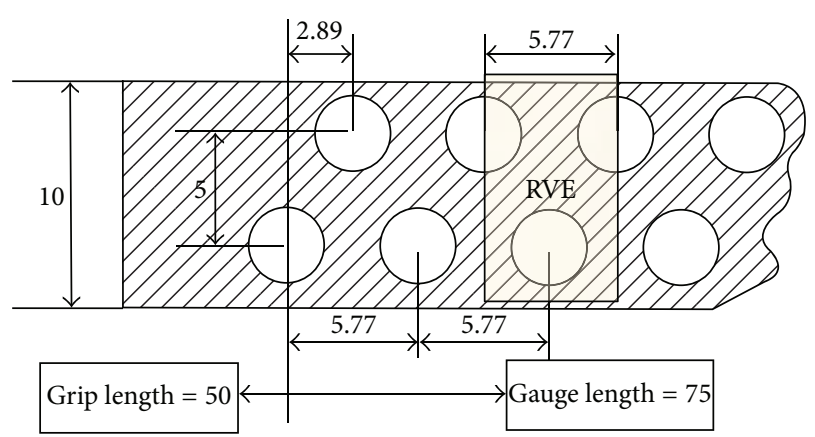

FIgURE 3: Two-dimensional drawing of test specimen.



FIGURE 4: FE model on one-fourth of RVE.



FIgURE 5: Load-displacement diagram of one Al-Fe specimen. 




FIGURE 6: Stress-strain plots of Al-Fe specimens.

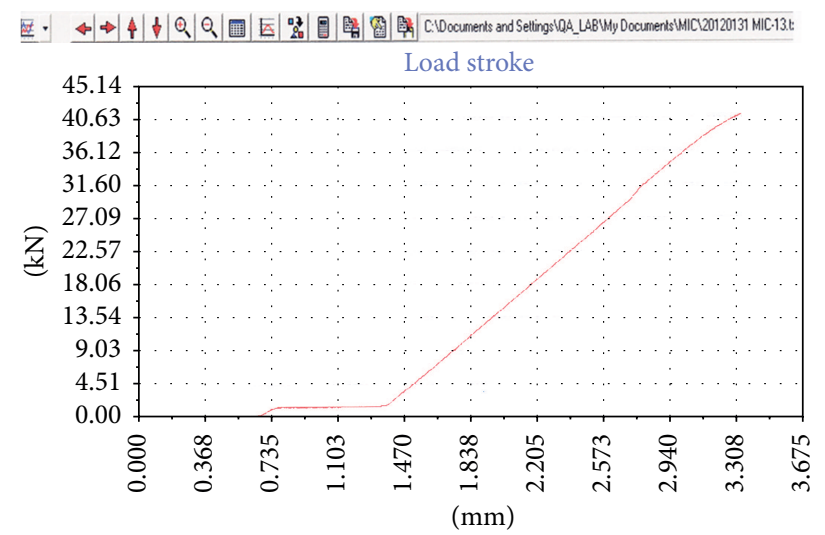

FIgURE 7: Load-displacement diagram of one Al-Cu specimen.

results have converged for this model. Symmetric boundary conditions are applied on negative faces of the Cartesian coordinate system which can be observed in Figure 4. Multipoint constraints are imposed on the boundary planes $x$, $y$, and $z$ to ensure uniform strain in respective directions. A uniform tensile load of $1 \mathrm{MPa}$ is applied on the $x$-face to observe a uniaxial state of stress that facilitates usage of simple Hooke's law for calculating Young's modulus, while the fibres are parallel to $z$-axis. Nonlinear contact elements have been employed at the interface of the fibre and matrix to allow possible debond under tensile load and contact in compression as it happens in experimentation. This model is necessitated as the fibres in the specimen are not bonded to the matrix by any mechanical means. Figure 3 shows two dimensional drawing of the actual specimen with RVE highlighted. Figure 4 shows FE model on one fourth of RVE.

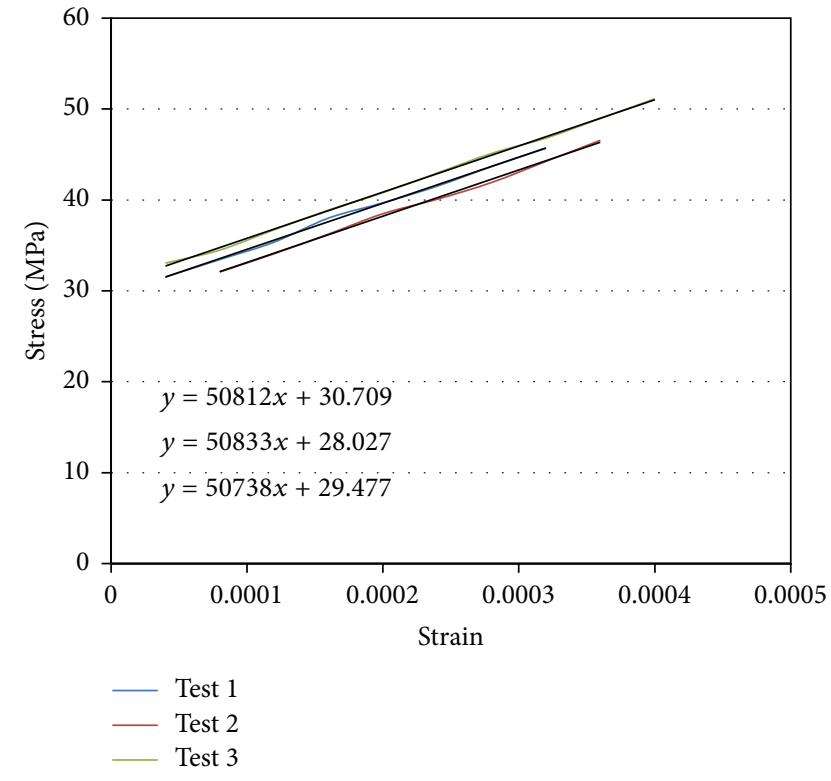

FIGURE 8: Stress-strain plots of Al-Cu specimens.

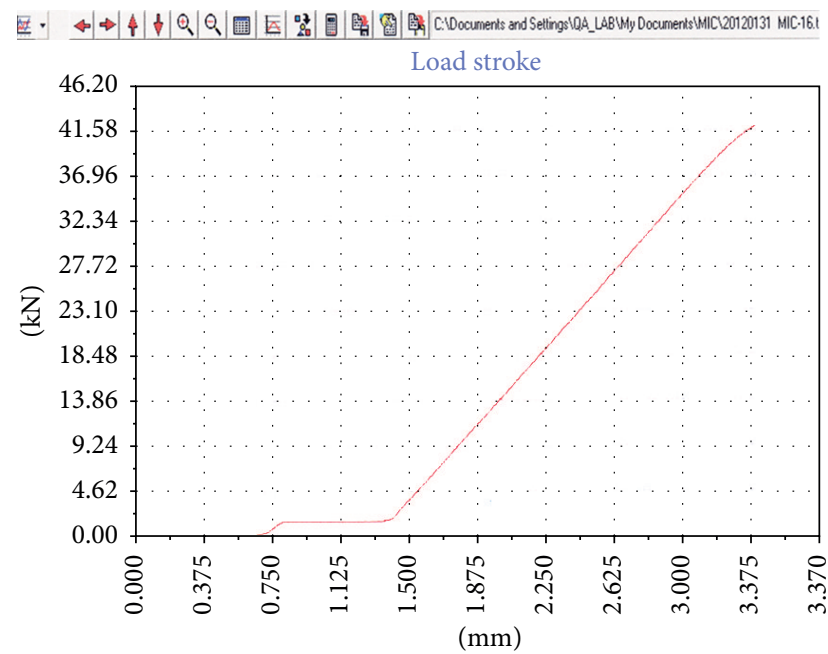

FIGURE 9: Load-displacement diagram of one Al-void specimen.

\section{Results and Discussions}

The purpose of simulating geometrically accurate specimen of different combination of materials appears to be served as the entire specimens tested have shown consistent results. The closeness of each group of results indicates the precision of the exercise. For each material, three samples are tested and Figures 5, 7, and 9 show one load-displacement plot each of $\mathrm{Al}-\mathrm{Fe}, \mathrm{Al}-\mathrm{Cu}$, and $\mathrm{Al}-\mathrm{Void}$ specimen, respectively, as printed by the UTM. Figures 6,8 , and 10 show the stress-strain plots prepared from the data taken from UTM in the same order as mentioned above. These plots show the linear portion of the stress-strain curve for three identical test specimens. It is observed that in case of $\mathrm{Al}$-void all the three curves are collinear (Figure 10) while in the case of $\mathrm{Al}-\mathrm{Cu}$, the plots are close to one another (Figure 8). However, in case of Al-Fe, one 




Figure 10: Stress-strain plots of Al-void specimens.

TABLE 2: Comparison of experimental and FEM results with \% error.

\begin{tabular}{lccc}
\hline & Aluminium-Fe & Aluminium-Cu & Aluminium-void \\
\hline Test 1 & 51.091 & 50.812 & 49.721 \\
Test 2 & 51.067 & 50.833 & 49.879 \\
Test 3 & 51.127 & 50.738 & 49.648 \\
Exptl. average & $\mathbf{5 1 . 0 9 5}$ & $\mathbf{5 0 . 7 9 4}$ & $\mathbf{4 9 . 7 4 9}$ \\
FEM & $\mathbf{5 0 . 0 8 7}$ & $\mathbf{5 0 . 0 0}$ & $\mathbf{4 9 . 5 7}$ \\
Error & $\mathbf{1 . 9 7 \%}$ & $\mathbf{1 . 5 6 \%}$ & $\mathbf{0 . 3 6 \%}$ \\
\hline
\end{tabular}

of the plots differs from the other two which could be due to experimental deviations from case to case. Young's modulus of each material from each test is determined from the slope of stress-strain curve of the respective plot. The average Yong's modulus from three tests is taken for comparison with FE results. The results are compiled in Table 2. Since FE and experimental results are in close agreement, it is felt that the magnitude of deviation in case of one of Al-Fe results is felt insignificant.

In all the three composites, matrix is commonly aluminium. It can be observed from the results that the Young's modulus of each composite is proportional to the Young's modulus of the fiber material. It can be observed that the differences between experimental FEM results for all the three combinations of materials are very much within acceptable limits which proves the reliability of FEM in predicting transverse modulus. Thus, it can be inferred that FEM can be used to effectively to predict transverse moduli of unidirectional fibre reinforced composites with hexagonal RVE in similar conditions. Further to this, it can be inferred that one can go for two metal combinations of materials, preferably with low fiber-matrix property mismatch, if one wants to study the influence of interface influence on the composite properties. Otherwise, void-like fiber is the best option for validation.

\section{Conclusions}

Transversely isotropic composite specimens that can be closely modelled in FEM are simulated, fabricated, and tested with two metal combinations. Equivalent FE models are designed and analysed under similar load conditions. Experimental and FE results are found to be very close with marginal deviations. The reliability of FEM to predict the transverse modulus of fibre reinforced composites is thus proved. This procedure finds its application in predicting transverse modulus of FRP composites of any combination reducing physical testing.

\section{References}

[1] I. M. Daniel and O. Ishai, Engineering Mechanics of Composite Materials, Oxford University Press, 1994.

[2] R. M. Jones, Mechanics of Composite Materisls, Taylor and Francis, 1999.

[3] A. K. Kaw, Mechanics of Composite Materials, CRC Press, 1997.

[4] E. Jacquet, F. Trivaudey, and D. Varchon, "Calculation of the transverse modulus of a unidirectional composite material and of the modulus of an aggregate: application of the rule of mixtures," Composites Science and Technology, vol. 60, no. 3, pp. 345-350, 2000.

[5] J. C. Halpin and J. L. Kardos, "The Halpin-Tsai equations: a review," Polymer Engineering and Science, vol. 16, no. 5, pp. 344352, 1976.

[6] L. E. Neilson, "Generalized equation for the elastic moduli of composite materials," Journal of Applied Physics, vol. 41, no. 11, pp. 4626-4627, 1970.

[7] T. J. Hirsch, "Modulus of elasticity of concrete affected by elastic moduli of cement paste matrix and aggregate," ACI Journal, vol. 59, no. 3, pp. 427-452, 1962.

[8] G. Kalaprasad, K. Joseph, S. Thomas, and C. Pavithran, "Theoretical modelling of tensile properties of short sisal fibrereinforced low-density polyethylene composites," Journal of Materials Science, vol. 32, no. 16, pp. 4261-4267, 1997.

[9] A. B. D. Morais, "Transverse moduli of continuous-fibre-reinforced polymers," Composites Science and Technology, vol. 60, no. 7, pp. 997-1002, 2000.

[10] H.-Z. Shan and T.-W. Chou, "Transverse elastic moduli of unidirectional fiber composites with fiber/matrix interfacial debonding," Composites Science and Technology, vol. 53, no. 4, pp. 383-391, 1995.

[11] S. Mistou, M. Karama, R. EL Guerjouma, D. Ducret, J. P. Faye, and B. Lorrain, "Comparative study on the determination of elastic properties of composite materials by tensile tests and ultra sound measurement," Journal of Composite Materials, vol. 34, no. 20, pp. 1696-1709, 2000.

[12] L. Stagni, "Effective transverse elastic moduli of a composite reinforced with multilayered hollow-cored fibers," Composites Science and Technology, vol. 61, no. 12, pp. 1729-1734, 2001.

[13] M. Z. Khelifa, M. S. Abdullateef, and H. M. Al-Shukri, "Mechanical properties comparison of four models, failure theories study and estimation of thermal expansion coefficients for artificial Eglass polyester composite," Engineering \& Technical Journal, vol. 29, no. 2, pp. 278-292, 2011. 
[14] D. S. Li and M. R. Wisnom, "Finite element micromechanical modelling of unidirectional fibre-reinforced metal-matrix composites," Composites Science and Technology, vol. 51, no. 4, pp. 545-563, 1994.

[15] P. S. Theocaris, G. E. Stavroulakis, and P. D. Panagiotopoulos, "Calculation of effective transverse elastic moduli of fiberreinforced composites by numerical homogenization," Composites Science and Technology, vol. 57, no. 5, pp. 573-586, 1997.

[16] Z. H. Karadeniz and D. Kumlutas, "A numerical study on the coefficients of thermal expansion of fiber reinforced composite materials," Composite Structures, vol. 78, no. 1, pp. 1-10, 2007.

[17] B. Pal and M. R. Haseebuddin, "Analytical estimation of elastic properties of polypropylene fiber matrix composite by finite element analysis," Advances in Materials Physics and Chemistry, vol. 2, no. 2, pp. 23-30, 2012.

[18] A. S. Prasad, K. V. Ramana, V. B. K. Murthy, and G. S. Rao, "Role of Finite Element Method (FEM) in predicting transverse modulus of Fiber-Reinforced Polymer (FRP) composites: a revelation," International Journal of Physical Sciences, vol. 8, no. 25, pp. 1341-1349, 2013. 



Submit your manuscripts at http://www.hindawi.com
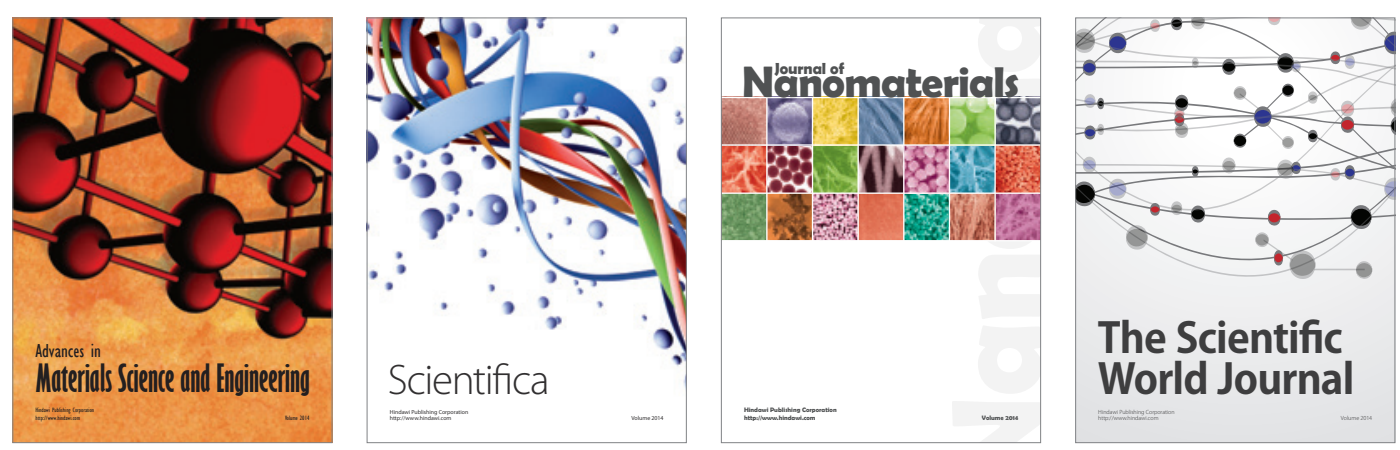

\section{The Scientific World Journal}
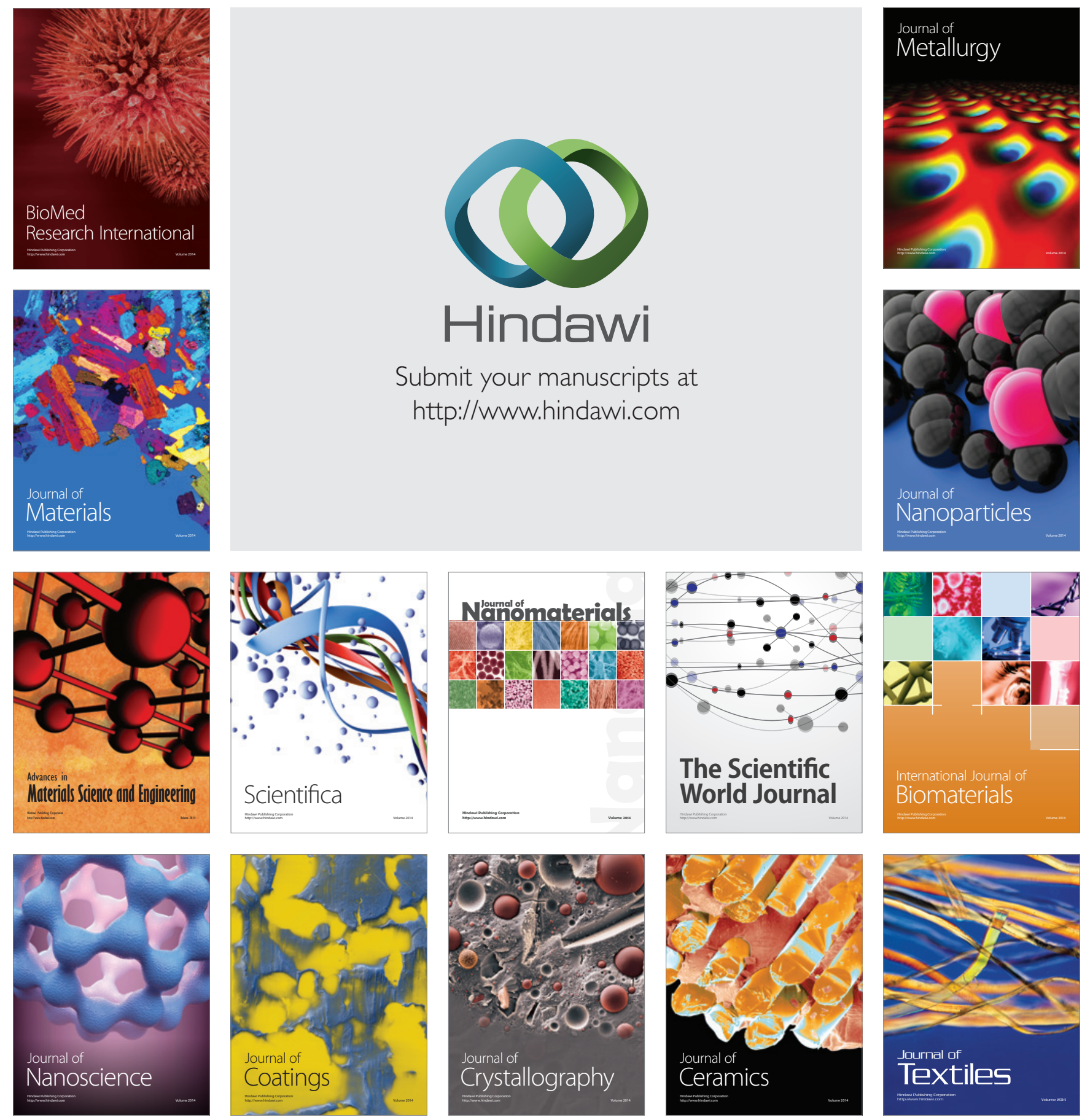